\title{
Development and implementation strategies of a nurse-led symptom self- management program in outpatient cancer centres: The Symptom Navi(C) Programme
}

\author{
Marika Bana $^{\text {a,b }}$, Karin Ribi ${ }^{\text {b,c }}$, Susanne Kropf-Staub ${ }^{\text {d }}$, Ernst Näf ${ }^{e}$, Monique Sailer Schramm, ${ }^{\mathrm{a}, 1}$ \\ Sabin Zürcher-Florin ${ }^{\mathrm{d}}$, Solange Peters ${ }^{\mathrm{f}}$, Manuela Eicher ${ }^{\mathrm{b}, \mathrm{f}, *}$ \\ ${ }^{a}$ University of Applied Sciences and Arts Western Switzerland HES-SO, School of Health Sciences, Route des Arsenaux 16a, CH-1700, Fribourg, Switzerland \\ ${ }^{\mathrm{b}}$ Institute of Higher Education and Research in Health Care IUFRS, Faculty of Biology and Medicine, University of Lausanne and Lausanne University Hospital, SV-A \\ Secteur Vennes, Route de la Corniche 10, CH-1010, Lausanne, Switzerland \\ ${ }^{\mathrm{c}}$ International Breast Cancer Study Group (IBCSG), Effingerstrasse 40, CH-3008, Bern, Switzerland \\ ${ }^{\mathrm{d}}$ Hospital Group Lindenhof, Lindenhof, Bremgartenstrasse 117, Postfach, CH-3001, Bern, Switzerland \\ e Department of Practice Development in Nursing, Solothurner Spitäler, Kantonsspital Olten, Baslerstrasse 150, CH-4601, Olten, Switzerland \\ ${ }^{\mathrm{f}}$ Department of Oncology, Centre Hospitalier Universitaire Vaudois (CHUV), Rue du Bugnon 21, CH-1011, Lausanne, Switzerland
}

\section{A R T I C L E I N F O}

\section{Keywords:}

Behaviour change

Complex intervention

Implementation research

Neoplasm

Self-management

Symptom management

\begin{abstract}
A B S T R A C T
Purpose: The Symptom Navi@ Programme (SNCP) is a structured nurse-led intervention supporting symptom self-management in cancer patients. We describe the development and evaluation of the intervention, implementation strategy, and the evaluation of nurse training for the Symptom Navi@ Pilot Study.

Methods: The intervention was developed using multiple methods (e.g. literature synthesis, focus groups) to produce SN@P information leaflets (SN@Flyers in French and German) and standardised training for nurses to deliver semi-structured consultations. We evaluated the SNCP using online surveys, focus groups, interviews, and the Item-Content Validity Index (I-CVI). Nurse training was evaluated in relation to content, acceptability, and confidence in implementing the SN@P. We examined the association between scored on the Work-related Sense of Coherence (Work-SoC) scale and nurses' confidence in implementing the SNCP. Thematic analysis was used to analyse qualitative data. Quantitative data was descriptively analysed and the Kendall Tau test was employed for correlations.

Results: Patients and health care professionals confirmed that SN@Flyers and semi-structured consultations facilitated symptom self-management. Nurses considered training content/format acceptable and appropriate and felt confident in implementing the SNCP. Overall Work-SoC scores were correlated with nurses' confidence in implementing the $\mathrm{SNCP}\left(\mathrm{r}_{\pi}=.47, p=.04\right)$.

Conclusions: Health care professionals and cancer patients perceived the SN@P as a useful support. Successful implementation of the SNCP depends on centre-specific factors including time, resources and workflow. Clinical trial registry: NCT03649984 and SNCTP000002381.
\end{abstract}

\section{Introduction}

Evidence suggests that health care providers offer supportive care to meet physical, emotional, psychosocial, informational, and practical needs of patients diagnosed with cancer (Fitch, 2008). Oncology nurses are well situated to assist patients in communicating needs, values and preferences during chemotherapy (Armes et al., 2014; Ferrell et al., 2013) and to support ambulatory cancer patients with symptom selfmanagement (Charalambous et al., 2018; Coolbrandt et al., 2018; Wagland et al., 2015). A growing number of patients undergo outpatient cancer treatment and are at risk for multiple potential adverse events that require self-management (Giesinger et al., 2014; Lewis

\footnotetext{
${ }^{*}$ Corresponding author. Institute of Higher Education and Research in Health Care IUFRS, SV-A Secteur Vennes, Route de la Corniche 10, CH-1010 Lausanne, Switzerland. Tel.: + 41797013852 .

E-mail addresses: marika.bana@hefr.ch, marika.bana@unil.ch (M. Bana), karin.ribi@ibcsg.org, karin.ribi@ibcsg.org (K. Ribi), susanne.kropf@lindenhofgruppe.ch (S. Kropf-Staub), ernst.naef@spital.so.ch (E. Näf), monique.sailer@medizentrum.ch (M.S. Schramm), sabin.zuercher@lindenhofgruppe.ch (S. Zürcher-Florin), solange.peters@chuv.ch (S. Peters), manuela.eicher@chuv.ch, manuela.eicher@chuv.ch (M. Eicher).

${ }^{1}$ Present address: MediZentrum Täuffelen AG, Breitenfeldstrasse 4, CH-2575 Täuffelen, Switzerland.
} 
et al., 2015). Ambulatory cancer patients report on average eight cooccurring symptoms (Wagland et al., 2015). Consequently, patients need to know how to recognise, evaluate, interpret, monitor, and manage their symptoms (Coolbrandt et al., 2016, 2017). However, providing information alone is not sufficient to support patient symptom self-management (de Silva, 2011; McCorkle et al., 2011). Symptom self-management is a dynamic process that involves integrating adequate behaviours and strategies to prevent, relieve or decrease symptoms (Hoffman, 2013). The process includes managing symptoms and supportive treatments, dealing with emotional and physical consequences of the disease, and adaptive behaviours (Lorig and Holman, 2003; McCorkle et al., 2011). Therefore, it is recommended that symptom self-management be addressed at the start of anticancer treatment (Fitch, 2008). Additionally, evidence-based psycho-educational interventions guided by principles of behaviour change principles should be offered (Schofield and Chambers, 2015). Core elements for self-management educational interventions include facilitating problem solving and adequate decision-making skills, fostering patient self-efficacy for effectively communicating with health care professionals, tailoring recommendations to the individual's situation, and defining goals with action plans (Howell et al., 2017).

Best practices include standardising self-management support to maintain effectiveness and sustainability (Schofield and Chambers, 2015) and providing detailed descriptions of interventions to facilitate behaviour change (Michie et al., 2014). Moreover, it is important to employ well-developed training techniques to facilitate effective implementation (Michie et al., 2009). Evidence supports the importance of providing symptom self-management interventions within the context of a multi-professional health care team (Howell et al., 2017).

The Capability Opportunity Motivation - Behaviour (COM-B) model (Michie et al., 2011) identifies three essential conditions for behaviour change: capabilities, opportunities, and motivation. To facilitate behaviour change in practice, nine intervention functions should be considered (educating, persuading, incentivising, coercing, training, enabling, modelling, environmental restructuring, and restricting). In addition, seven policy aspects (guidelines, environmental/social planning, communication/marketing, legislation, service provision, regulation, and fiscal measures) should be taken into account (Michie et al., 2011).

Successful implementation of complex interventions/new tasks into a service may depend on contextual and work-related factors (e.g. usual workload, available resources for providing services, access to private rooms for patient conversations) (Bryant-Lukosius et al., 2016). Work resources and demands are correlated with an individual's perceived work-related sense of coherence. Work-related sense of coherence includes perceived comprehensibility, manageability and meaningfulness of the work situation and is a mediator between job resources and employee work engagement (Vogt et al., 2013).

Despite a growing body of evidence of the importance of symptom self-management support for cancer patients, nurse-led interventions are rarely implemented into routine clinical practice (Charalambous et al., 2018). In Switzerland, patients report needing more information and support to self-manage their symptoms during cancer treatment (Dubey et al., 2015; Serena et al., 2012). To address this need, Swiss oncology nurses initiated the development of the Symptom Navi( Programme (SN@P) in 2011. The SNCP consists of 16 evidence-based written information leaflets (Symptom Navi@ Flyers, SNCFlyers), and a training manual for nurses to deliver semi-structured nurse-led consultations. SNCFlyers provide patients with structured information on self-management options to relieve common physical and psychosocial symptoms. Semi-structured nurse-led consultations using SN@Flyers begin at the onset of a treatment. Nurses tailor consultations to the prescribed therapy in order to support patient's individual symptom self-management. Each patient should receive at least two consultations. If symptom intensity and/or patient needs persist, semi-structured consultations are intended to continue until patients successfully achieves alleviation of symptoms via self-management. Nurse training is standardised to facilitate the semi-structured approach of the intervention.

\section{Aims and objectives}

We describe the development of the SNCP, its implementation and evaluation of the SNCP nurse training. Our objectives are to:

i. Summarise the development of the SNCP and evaluation of SNCFlyers by patients and health care professionals;

ii. Describe the development and content of the SN@P training for nurses;

iii. Investigate oncology nurses' evaluation of the content of the SNCP training, its acceptability, and to describe nurses' confidence in implementing the SNCP into practice;

iv. Describe the association between nurses' confidence in implementing the SNCP within their clinical daily routines and their current work situation (contextual/work-related factors).

\section{Methods}

The SNCP (SNCFlyers, semi-structured nurse-led consultations, and training) has been developed over several years in a sequential process (Fig. 1). Development and evaluation phases employed an iterative process. We used multiple methods to develop the SNCP including literature synthesis, consensus panels, online surveys, focus group discussions, and interviews with cancer patients and health care professionals. A description of the development process of SNCFlyers and semi-structured consultations has been previously published in German (Kropf-Staub et al., 2017a, 2017b). Herein, we provide a comprehensive overview of the development of the Symptom Navi@ Pilot Study (NCT03649984) and evaluation of the nurse training program. An ongoing two-arm cluster-randomised study (complemented with qualitative methods) is underway to assess feasibility and determine preliminary effectiveness of the SNCP (approved by cantonal Swiss ethic committee, KEK-BE: 2017-00020) (Bana et al., 2019).

\subsection{Development of $S N @$ Flyers and nurse-led semi-structured consultations (2011-2014)}

SNCFlyers were developed for symptoms frequently experienced during anticancer treatments (Reeve et al., 2014). The SNCFlyers synthesize international evidence-based recommendations/guidelines (Irwin and Johnson, 2014) and recent literature reviews were incorporated into (Cockle-Hearne and Faithfull, 2010; Griffiths et al., 2012; Hammer et al., 2015; Luckett et al., 2013; McCorkle et al., 2011). SNCFlyer recommendations aim to support patient self-management and identify steps patients can take to relieve specific symptoms.

To design the SNCFlyers, we assessed Swiss cancer patients' needs and preferences in a series of patient focus group discussions in collaboration with members of the Swiss Oncology Nursing Society and the University of Applied Science and Arts Western Switzerland, School of Health Sciences in Fribourg. This process led to three alternate designs for SN@Flyers. All versions included: a) symptom intensity levels (mild, moderate and severe), b) descriptions of physical changes patients may observe related to respective intensity level, and c) evidence-based symptom self-management recommendations across intensity levels. The three versions used different colour-codes to visually identify symptom intensity levels and different symbols (emoticons) relating to patients' subjective rating of symptom intensity. SNCFlyers are available in both German and French.

SNCFlyers were provided to patients during individual, face-toface, semi-structured nurse-led consultations guided by principles of therapeutic patient education (Bodenheimer et al., 2002; Howell et al., 2017; McCorkle et al., 2011; Schofield and Chambers, 2015). The self- 


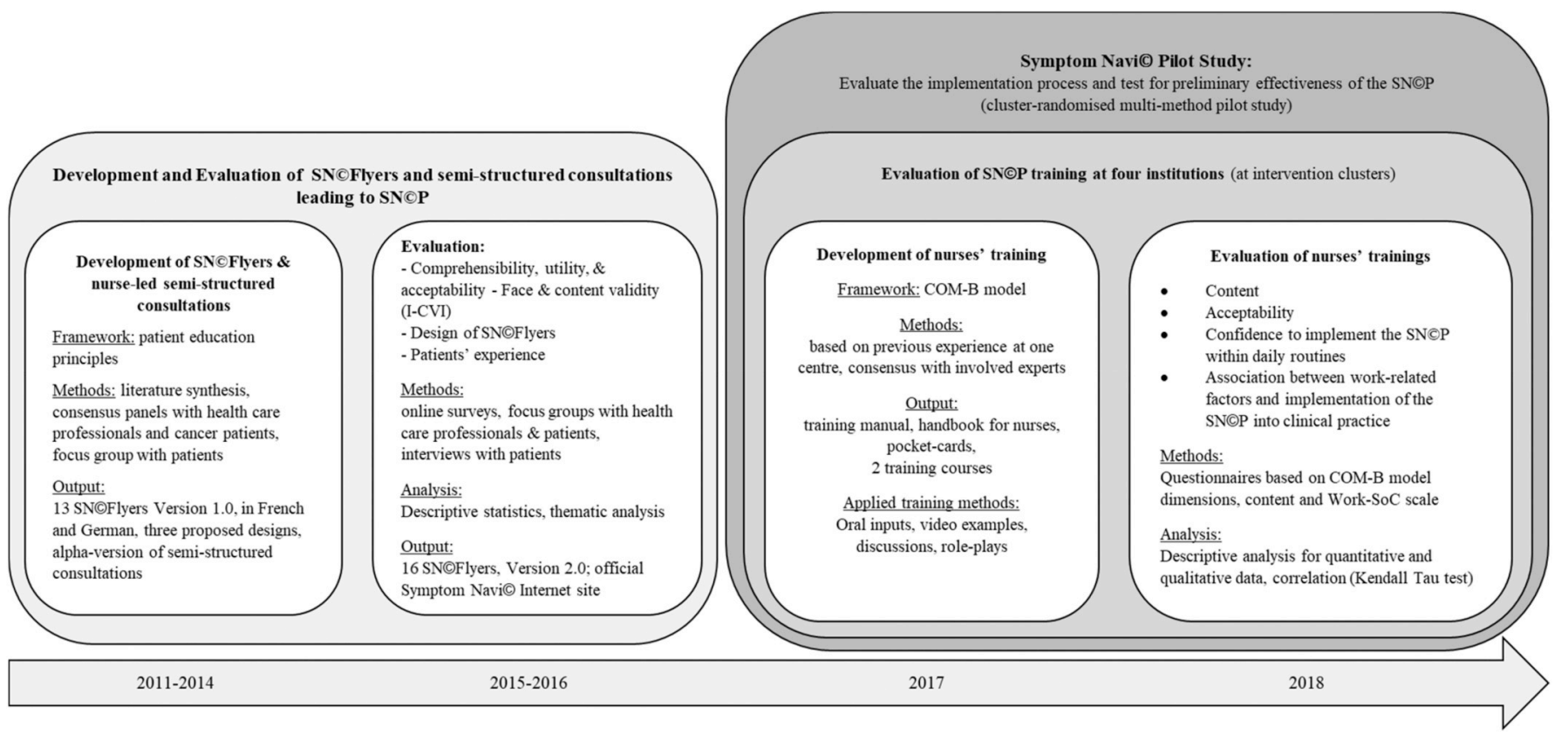

Fig. 1. Development and Evaluation of the Symptom Navi@ Program 2011 to 2018

Legend SN@P: Symptom Navi@ Programme; SNCFlyers: Symptom Navi@ Flyers; I-CVI: Item-Content Validity Index; COM-B model: Capability Opportunity Motivation - Behaviour model; Work-SoC: Work-related Sense of Coherence.

Table 1

Symptom Navi@ Program six key-elements of nurse-led semi-structured consultations.

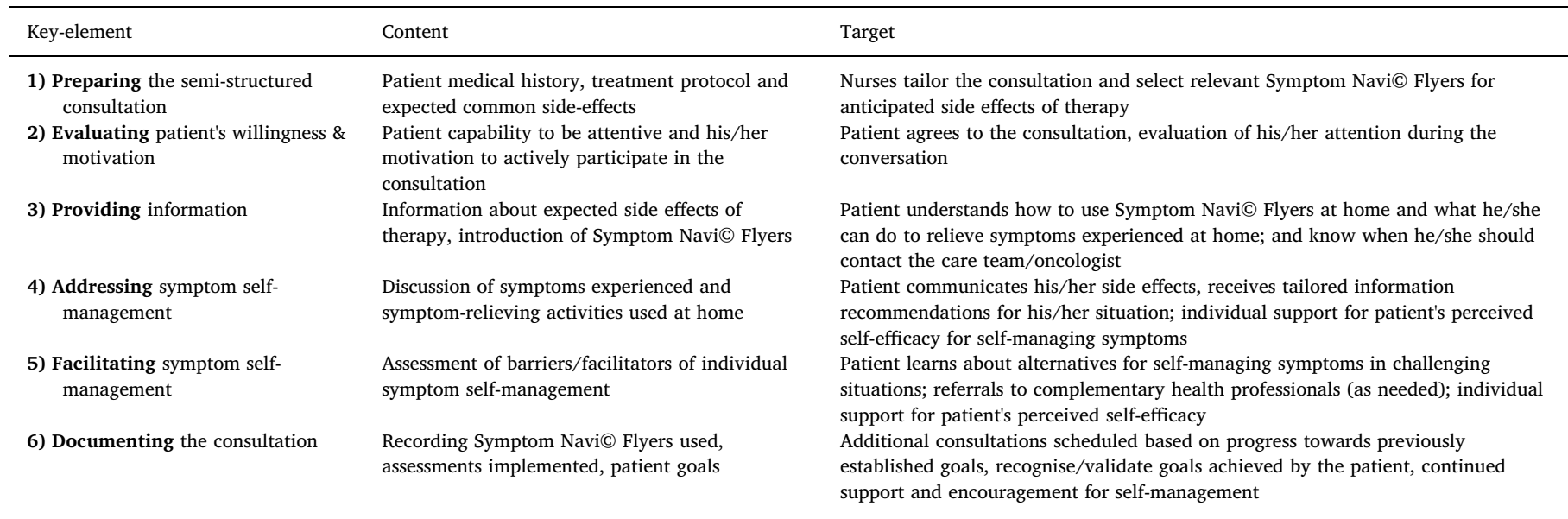

Six key-elements are tailored to individual patient needs in an iterative fashion rather than a linear consultation structure. Each patient receives at least two face-toface semi-structured consultations at outpatient cancer centre during chemotherapy.

management education intervention was intended to be delivered by graduate-level nurses to complement standard nursing care in daily clinical practice at the cancer centre. Broadly, semi-structured consultations focused on patient's needs and building a therapeutic partnership with the patient. Importantly, the semi-structured consultations were based on six key-elements (Table 1). Two key-elements specifically focused on supporting self-management strategies: addressing symptom self-management and facilitating self-management (Table 1, key elements 4, 5). Key element 5 (facilitating self-management) included assessing patient self-efficacy for self-management. Nurses provided at least two semi-structured consultations with each patient at the beginning of systemic treatment. Ideally, the intervention took place in a separate, private room.

The first consultation included key elements 1-3 and 6 (Table 1). Initial goals were to inform the patient about expected symptoms and how to recognise, evaluate and interpret symptoms. Nurses tailored the initial semi-structured consultations according to the patient's individual treatment protocol. Patients also received additional written information (e.g. Swiss Cancer League brochures) as part of the cancer centre's standard care practices. The first consultation was planned to occur within the first two or three systemic treatments (i.e. three to four weeks). From the second consultation on, nurses included all six key elements and focused on symptom self-management behaviours.

If symptoms persisted, nurses continued providing semi-structured consultations based on patient needs until symptom self-management was achieved. Nurses' fidelity to the intervention (as delineated in the training manual) was assessed as part of the Symptom Navi@ Pilot Study and will be published elsewhere.

\subsection{Evaluation of SN-Flyers (2015-2016)}

SNCFlyers were evaluated using anonymised online surveys and 
focus groups conducted in French and German by one of the authors (ME) and a scientific collaborator not familiar with the study. Health care professionals, patients and family members evaluated 1) understandability, utility and acceptability of SNCFlyers; 2) preferred design among the three versions; and 3) face validity of evidence-based recommendations. Understandability, utility, acceptability and preferred design version of SNCFlyers were evaluated in three patient focus groups and an online survey of both patients and health care professionals. Focus groups were conducted using an interview guide and qualitative data were analysed using thematic analysis (Braun and Clarke, 2006). Three groups of health care professionals and cancer patients ( $n=7-9$ per group) rated five to six SNCFlyers in an online survey. Invited participants were purposefully sampled to represent a variety of health care professions, language regions and different cancer diagnoses. Participants rated each SN@Flyers recommendation (item) as 'not relevant', 'somewhat relevant', 'quite relevant', or 'highly relevant' per the Item-Content Validity Index (I-CVI) (Polit and Beck, 2006). To analyse I-CVI overall score for each SN@Flyer, we transformed answers into a 'dummy' variable ('not relevant' and 'somewhat relevant' $=0$, 'quite relevant' and 'highly relevant' $=1$ ). Participants were also invited to provide open-ended comments on each item. A committee of four academic oncology nursing experts led the SNCFlyer evaluation.

The online survey including 48 patients and health professionals revealing excellent face validity with overall I-CVI of 0.95 and 0.9 for French and German versions, respectively (range (French): 0.43-1.0, (German): $0.33-1.0,1.0=$ maximum validity). Patient focus group discussions ( $\mathrm{n}=3$, two in German, one in French) included 14 patients and one family member. Two health care professional focus groups were conducted involving 16 professionals (Table 2). Participants thought SN@Flyers were easy to understand, provided important information and facilitated rating of symptom intensity. The design using smiley-emoticons and colour coding (green $=$ mild, yellow $=$ moderate, red $=$ severe) was the preferred design by patients and health care professionals alike. Subsequently, SN@Flyers were refined (Version 2.0) based the online survey results and focus group discussion. The final SNCFlyers version included 16 symptom-specific flyers (three flyers were added to the first version) (Bana et al., 2019).

\subsection{Patients experience with semi-structured consultations}

Semi-structured interviews (in German) were conducted (author: SKS) to explore patients' experiences with SN@Flyers and semi-structured consultations. Patients were asked how they used the SNCFlyers and about their experiences with nurse-led consultations and perceived symptom self-management support. An interview guide included five open-ended questions: 'How did you perceive the conversation on SNCFlyers? Which information were important for you? How was your experience with the SN@Flyers? Are there any kind of questions that could not be answered? Is there an issue you would like to add?'.

Table 2

Focus group participants.

\begin{tabular}{|c|c|c|c|}
\hline $\begin{array}{l}\text { Health care professionals } \\
(n=16)\end{array}$ & $\mathrm{n}$ & $\begin{array}{l}\text { Patients and family members } \\
(n=15)\end{array}$ & $\mathrm{n}$ \\
\hline German-speaking & 13 & German-speaking & 9 \\
\hline French-speaking & 3 & French-speaking & 6 \\
\hline Nurses in clinical practice & 3 & Cancer diagnosis: & \\
\hline Nurses in education and research & 8 & Gynaecological & 4 \\
\hline Oncologists & 3 & Colo-rectal & 4 \\
\hline \multirow[t]{3}{*}{ Graphic design specialists } & 2 & Lung & 2 \\
\hline & & Other $^{\mathrm{a}}$ & 5 \\
\hline & & Family members & 1 \\
\hline
\end{tabular}

${ }^{\text {a }}$ Cancer diagnoses: testicular, pancreatic, hepatic, chronic lymphatic leukaemia.
Table 3

Themes and sub-themes from semi-structured interviews with cancer patients $(\mathrm{n}=10)$.

\begin{tabular}{ll}
\hline Main themes & Sub-themes \\
\hline Being emotionally challenged & Having to decide alone \\
& Desire to survive \\
& Uncertainty and anxiety for therapy \\
& Insecurity in everyday life \\
Meaning of social support for self- & Motivated by family members \\
management & Becoming strong to reduce anxiety \\
& Self-management experiences from peers \\
Self-management support based on & Patient-centeredness is crucial for care \\
needs & Talking to different health care \\
& professionals is complementary \\
& Enhance competencies by conversations \\
& and daily tips \\
& Relief by proactive information \\
Orientation by SNCFlyers & Alleviation by need-oriented and serious \\
& source \\
& Gain overview \\
& Evaluate intensity \\
& Develop capacity to act \\
& Recognise urgency/priority \\
& Avoid too much information ("hyper \\
information") & Apply appropriate everyday \\
achieve manageability of symptoms & recommendations \\
& Become active \\
& \\
&
\end{tabular}

Interviews were audio-recorded, transcribed verbatim, and analysed using thematic analysis (Braun and Clarke, 2006).

In total, $10 / 15$ eligible patients (i.e. received the $\mathrm{SN} C \mathrm{P}$ at a regional Swiss hospital) were interviewed. Participated semi-structured interviews: Seven women and three men (35-77 years old) with different cancer diagnoses were interviewed. Thematic analysis revealed five main themes: being emotionally challenged, meaning of social support for self-management, self-management support based on needs, orientation by SNCFlyers, and achieve manageability of symptoms. Themes and sub-themes are presented in Table 3.

\subsubsection{Developing $S N @ P$ nurse training program (2017)}

The training program for nurses aimed to standardise the procedure, ensure that the implementation of the SNCP could be replicated at different sites and effectively integrated into daily clinical routines. The nurse training module was based on clinical experience and drew on the COM-B model as a guiding theoretical model (Michie et al., 2011). The COM-B model posits that capability (i.e. knowledge and skills) and opportunities (i.e. external work-related resources needed for the target behaviour) influence motivation (intrapersonal conditions such as individual habits, analytical and emotional processes) to perform a target behaviour. The three dimensions (capability, opportunities, motivation) are inter-related (Fig. 2).

We designed two consecutive, complementary training courses. The initial training (approximately $4 \mathrm{~h}$ ) was followed by a subsequent, separate 2-h training (Fig. 2). Both courses aimed to support nurse behaviour change from current practice (i.e. providing information) to perform interventions supporting patient symptom self-management. Teaching methods included didactic oral presentations, video examples of nurse-led consultations and interactive group exercises. The initial training introduced the SN@Flyers, reviewed the six-key elements for semi-structured consultations (Table 1), summarized principles of therapeutic patient education, and outlined basic motivational interviewing techniques. Following the initial training, nurses applied the SNCP at their centre over the next four to six weeks.

The follow-up training had two goals: 1) to support nurses' motivation for implementing the $\mathrm{SN} \odot \mathrm{P}$ at their centres, and 2) to identify potential barriers to implementing the $\mathrm{SN} C \mathrm{P}$ within daily routines and discuss opportunities to overcome identified roadblocks. Discussion 


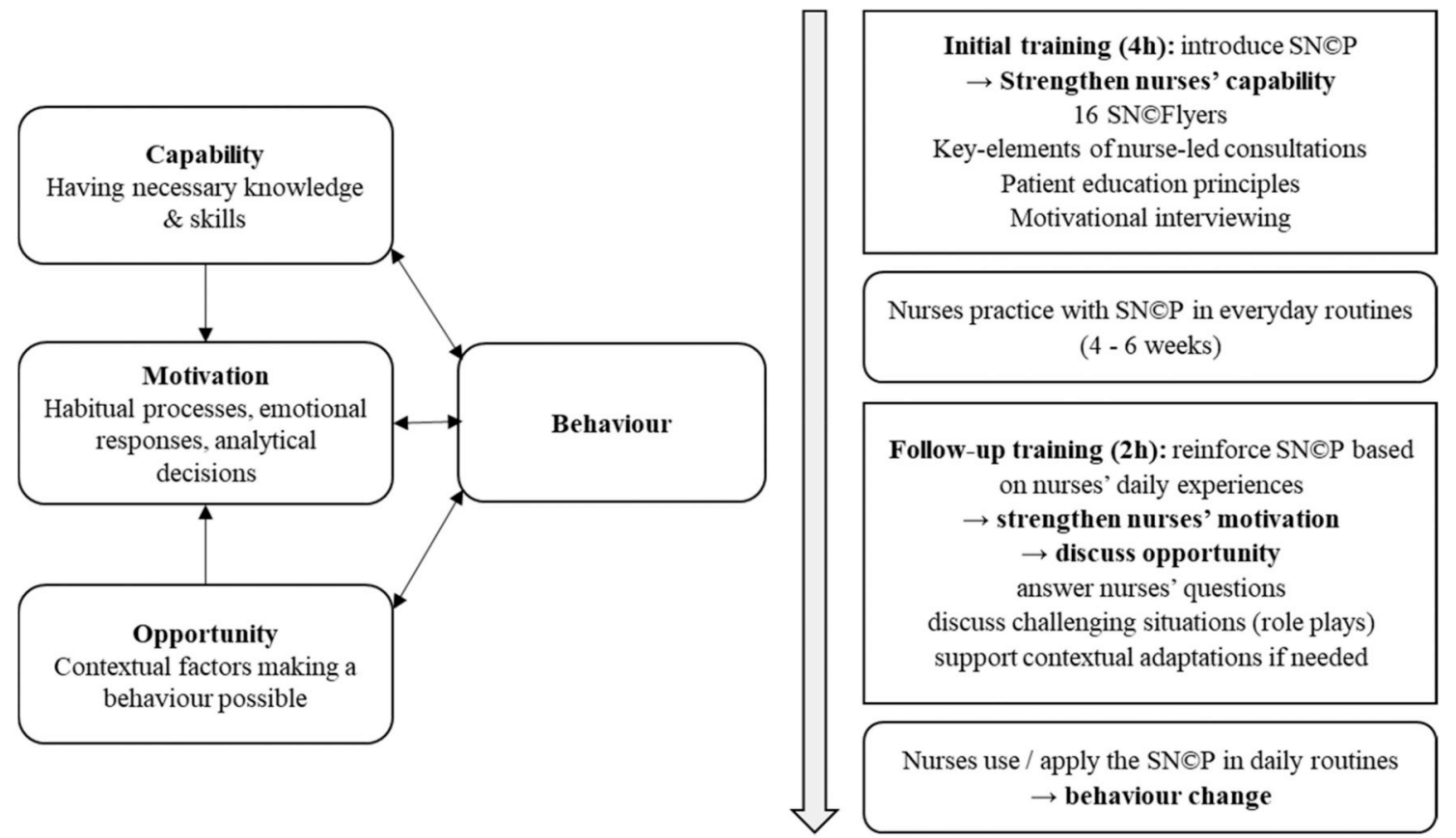

Fig. 2. Nurse training content and procedure, based on COM-B model (Michie et al., 2011)

Legend SNCP: Symptom Navi@ Programme; SNCFlyers: Symptom Navi@ Flyers.

focused on nurses' initial experiences with implementing the SN@P into their daily routine. Between the courses, the nurses were asked to prepare for the follow-up training by recording their experiences and reflections to inform the follow-up training and support an interactive and participative exchange (Hild, 2013).

Training content was based on standardised material. Each centre received a training manual and nurses' handbook. The training manual included details on the theoretical framework, content and procedures of the SNCP. The training manual was developed by four health care experts from Swiss hospitals, European universities, and the SNCP steering committee (the training manual in German is available from the corresponding author upon request). The nurse's handbook was an abbreviated version of the training manual written in everyday (lay) language to facilitate nurses' in delivering semi-structured consultations. Additionally, participating nurses received laminated pocket cards and copies of the materials used in the training sessions. Pocket cards included model questions related to each key-element of the semistructured consultations. Recommended questions were tailored to support patients' symptom self-management and based on 'motivational interviewing' communication styles (i.e. guiding - following - directing the conversation) (Rollnick et al., 2008). The goal of these pocket cards was to provide a quick reference familiarising nurses with the semistructured consultations and support their motivation to deliver the $\mathrm{SN} C \mathrm{P}$. The training program was reviewed and approved by the SNCP steering committee - consisting of two clinical experts in oncology nursing, a nursing manager, and two study researchers. The committee also identified two clinical oncology-nursing specialists (who were experienced lecturers) to conduct the nurse training programs.

\subsubsection{Evaluation of nurses' training (2018)}

The training evaluation took place at outpatient cancer centres in the German-speaking part of Switzerland that were randomised to the intervention group in the Symptom Navi@ Pilot Study. Registered nurses with at least a bachelor's degree or a diploma of higher education and who were salaried at the centre were eligible to participate in the pilot study. We excluded nurses who had worked less than one year in an oncology care setting. All available eligible graduate nurses at each centre participated in the training courses.
We described centres by type (e.g. breast cancer centre), number of employed nurses (full time equivalent), and mean number of anticancer treatments provided over the preceding month at study launch. We also collected characteristics of participating nurses including the total number of participating nurses, their type of oncology nursing education as well as and the number of nurses who participated in both training courses and the cumulative duration of training (in hours). Nurses completed 10 questions about the training content and their perceived confidence in implementing the SNCP as described in the training manual. Nurses rated the training manual content using a seven-point Likert-like scale ( $1=$ 'not at all' to $7=$ 'very much'). Questions were adapted to reflect the content of the two training sessions.

We assessed training acceptability using open-ended questions were included to capture both positive (i.e. "Particular positive during the initial/follow-up training was .... ") and negative feedback (i.e. "Rather inappropriate during the initial/follow-up training was .... "). We assessed contextual and work-related factors regarding available resources at the centre i.e. COM-B opportunity dimension (Michie et al., 2011). Nurses completed the Work-related Sense of Coherence (WorkSoC) scale (Bauer et al., 2015). This 9-item instrument uses a 7-point Likert-like scale to assess three-factors (comprehensibility, manageability, meaningfulness) and has good internal consistency (Cronbach $\alpha$ 0.83). Previous work has demonstrated higher Work-SoC scores are related to lower perceived work-related stress (Vogt et al., 2013). For this study, we assumed that lower work-related sense of coherence would represent increased work-related stress. We hypothesized that lower Work-SoC scores could be a barrier to implementing the SNCP at participating cancer centres.

Anonymous questionnaires were completed following training. Given the limited sample size, we calculated median, upper quartile (75\% percentile: evaluate whether a majority of nurses benefit from the training), interquartile range (IQR), minimum, and maximum values for each item assessing content and confidence. Narrative (open-ended) comments regarding acceptability were descriptively analysed and organised according to positive and negative keywords respectively. Following the follow-up training, nurses responded to a single question based on the COM-B model ('I feel confident to provide semi-structured 
consultations based on the SNCP within daily routines'). We employed the Kendall's tau test to analyse the relationship between perceived confidence and overall Work-SoC score. Statistical analyses were performed using STATA 15.0 software.

\section{Results}

Two master-prepared nurses from the development team trained 21 graduated nurses at four outpatient cancer centres (two general outpatient cancer centres, 2 gynaecological/breast centres). In total, 11 nurses participated in both training courses. Full time equivalent nursing staff at the participating centres ranged from 2.0 to 7.1. Approximately half $(10 / 21)$ of the nurses who participated in the training were specialised oncology nurses. On average, centres provided 44 anti-cancer treatments/day, and 2 treatments provided on two days per week. Three centres conducted both training courses while the fourth did not complete the second training due to a significant drop in newly diagnosed cancer patients. The number of participating nurses varied between three and eight nurses per centre. Initial training lasted between 3.5 and $4 \mathrm{~h}$, follow-up training between 1 and $2 \mathrm{~h}$.

\subsection{Nurses' evaluation of training content and acceptance of training}

Overall, the nurses considered the training content to be suitable and supportive for implementing the SN@P into clinical practice. Three quarters of the nurses gave the maximum rating of $7 / 7$ (most medians $=6 / 7$, IQRs $=1$ or 2 ). The video examples presented during the initial training received slightly lower ratings (median $=5 / 7, \mathrm{IQR}=2$ ) with larger variability (minimal rating $=2$, maximal rating $=6$ ) (Table 4).

Narrative feedback confirmed that both training courses were supportive and appropriate. Positive aspects included the interactive approach, use of reflections, and participant discussion. Exercises to familiarise nurses to the 16 SNCFlyers and the six key-elements of the semi-structured consultations were considered important. Nurses valued learning about the different approaches for supporting cancer patients' symptom self-management. Individual statements were consistent with feeling prepared to 'apply the SNCP in clinical daily routine'.

Table 4

Nurse Training evaluation of training duration, content and confidence in implementing the SNCP.

\begin{tabular}{llllll}
\hline Initial training $(\mathrm{n}=18)$ & Median & uq & IQR & Min & Max \\
\hline $\begin{array}{l}\text { Duration in hours } \\
\text { 1) Introduction was comprehensible* }\end{array}$ & 4 & & 0.5 & 3.5 & 4 \\
2) Oral presentation was informative and & 6 & 7 & 2 & 1.5 & 7 \\
$\quad$ comprehensible* & & 7 & 1 & 3 & 7 \\
3) I learned from video examples* & 5 & 5 & 2 & 2 & 6 \\
4) I am confident to practice semi-structured & 6 & 6 & 2 & 4 & 7 \\
$\quad$ consultations* & & & & & \\
5) I am confident to apply motivational & 6 & 7 & 2 & 5 & 7 \\
$\quad$ interviewing* & & & & & \\
Follow-up training (n = 14) & Median & uq & IQR & Min & Max \\
Duration in hours & 1.5 & & 0.9 & 1 & 2 \\
1) I asked my questions* & 6 & 7 & 2 & 4 & 7 \\
2) I got satisfying answers* & 6 & 7 & 1 & 4 & 7 \\
3) I feel empowered to apply SNCP** & 6 & 7 & 1 & 4 & 7 \\
4) I feel confident to explain SNCFlyers* & 6 & 7 & 1 & 4 & 7 \\
5) I feel confident to provide semi-structured & 6 & 7 & 2 & 4 & 7 \\
$\quad$ consultations based on the SN@P within & & & & & \\
$\quad$ daily routines* & & & & & \\
\hline
\end{tabular}

Legend: uq: upper quartile (75\% percentile); sd: standard deviation; SN@P: Symptom Navi@ Program; SN@Flyers: Symptom Navi@ Flyers (written in-

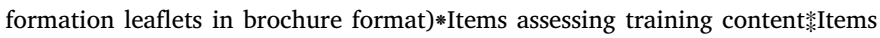
assessing confidence to implement the SN@P into practiceQuestion scales from $1=$ not at all, to $7=$ very much.
Nurses also reported some negative aspects. Several nurses missed the introduction of the Symptom Navi@ Pilot Study during the initial training and would have appreciated having a summary (recap) of the initial training at the beginning of the follow-up training. Some respondents considered the training sessions to be 'too long' in duration.

\subsection{Nurses' confidence to implement the SN@P within daily clinical routines}

In general, nurses felt confident to implement the SN@P within their daily clinical routines (Table 4). Three quarters of all nurses gave maximum confidence ratings ( $7 / 7)$ for four of five items. Only one ('I feel confident to practice semi-structured consultations') was lower at the completion of the first training (median $=6 / 7$, IQR $=2$ ). Respondents' ratings for 'feeling confident to practice semi-structured consultations' and 'use motivational interviewing' varied. The minimum and maximum ratings were 4 and 7 for 'practicing semistructured consultations', and 5 and 7 for 'using motivational interviewing' respectively. After the follow-up training, nurses felt confident to explain the SNCFlyers (median $=6 / 7$, IQR $=1$, range $=4-7$ ) and to implement semi-structured consultations based on the SNCP (median $=6 / 7, \mathrm{IQR}=2$, range $=4-7$ ). No narrative feedback were available to potentially explain the observed disparity.

\subsection{Association between Work-SoC score and nurses' confidence to implement the $\mathrm{SNCP}$}

Work-SoC scores for both trainings are presented in Table 5. We used the Kendall Tau test to assess the relationship between overall Work-SoC score (post follow-up training) and perceived confidence ('I feel confident to provide semi-structured consultations based on the SN@P within daily routines') (Table 4, question 5 for follow-up training). Work-SoC was positively correlated with perceived confidence in delivering the $\mathrm{SNCP}\left(\mathrm{r}_{\mathrm{T}}=.47, p=.04\right)$ (Fig. 3).

\section{Discussion}

\subsection{Development and evaluation of the $S N @ P$}

To our knowledge, the SNCP is one of the first prospectively evaluated, nurse-led standardised programs to support cancer patient symptom self-management during cancer treatments. The development of the SNCP comprised four steps with alternating development and evaluation phases. The SNCFlyers demonstrated excellent face validity and showed promising beneficial results for cancer patients. Involving relevant stakeholders is recommended for successful and sustainable implementation of complex interventions (Bryant-Lukosius et al., 2016; Craig et al., 2008), and to facilitate behaviour change of health care professionals (Michie et al., 2011). Accordingly, we involved patients, nurses, oncologists, and psycho-oncologists in all stages of the development process (Kropf-Staub et al., 2017a, 2017b).

Other programs have been developed to support cancer patients' symptom self-management. The SNCP differs from prior programs in several important ways. Patients only received SNCFlyers targeting their current, individual symptoms. This is in contrast to the CHEMOSUPPORT program, in which patients were provided an all-inclusive

Table 5

Overall Work-SoC scores for training 1 and 2 .

\begin{tabular}{lll}
\hline & Mean (sd) & Median (lq, uq) \\
\hline Training 1 & $5,41(0.78)$ & $5,33[4.77,6.11]$ \\
Training 2 & $5,08(0.80)$ & $4.55[4.55,5.66]$ \\
\hline
\end{tabular}

Legend: $\mathrm{lq}=$ lower quartile $(25 \%$ percentile $)$, uq $=$ upper quartile $(75 \%$ percentile). 


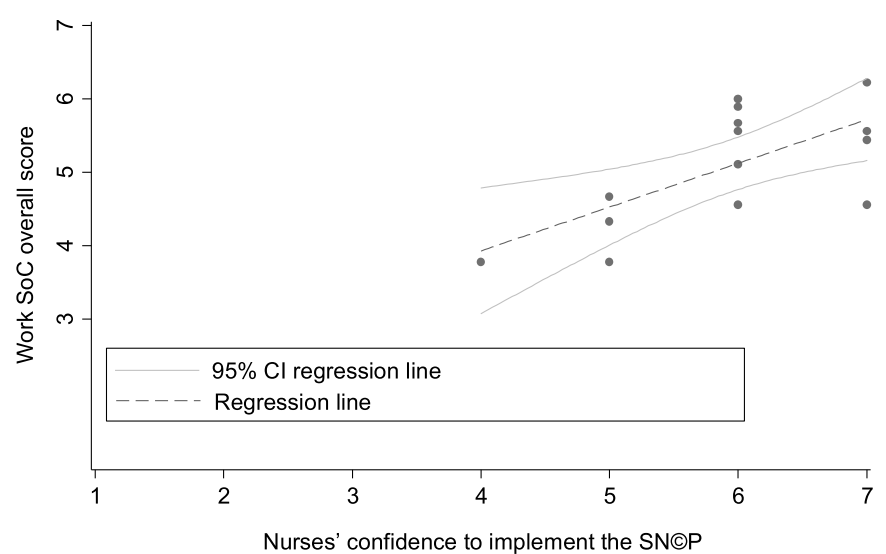

Fig. 3. Correlation between overall Work-SoC score and confidence in providing SNCP semi-structured consultations within daily routines $(\mathrm{n}=14)$; $\mathrm{r}_{\pi}=0.47, p=.04$.

booklet covering self-care and cancer (Coolbrandt et al., 2018). Selfmanagement interventions can be efficient if they provide patients with the most relevant information for their individual situation and do not overburden patients with too much or irrelevant information (Schofield and Chambers, 2015). The SNCP is intended for cancer patients irrespective of diagnosis and can be used during any stage of the illness trajectory. Implementing diagnosis-specific nurse-led intervention is not feasible in most ambulatory cancer centres. Programs such as the PROSPECTIV for prostate cancer survivors (Watson et al., 2018) may be too specific for the needs of patients in the general outpatient cancer setting.

\subsection{Nurse perspectives on acceptability and content of training}

Overall, the content of the SNCP training was well-received. However, minimum and maximum ratings for the video examples and introduction of the SNCP varied considerably. The observed difference may reflect different experiences in supporting cancer patients with symptom self-management as well as different educational preparation for working in oncology nursing. As such, tailoring training content to nurses' education level and individual needs may warrant consideration (Gaguski et al., 2017).

Narrative feedback received in open-ended responses was generally positive - further suggesting that the training content and format were acceptable. Nurses provided a few critical remarks regarding trainers' guidance through the courses and this will be a target for improvement in future training courses. The initial training helped most nurses become familiarised with the SNCFlyers and principles guiding the semistructured consultations. Importantly, nurses underscored the importance of learning from each other thus supporting the interactive approach to training. We aimed to train all graduate nurses at each centre for a total of $6 \mathrm{~h}$. However, only about half of nurses attended both training courses. This observation suggests that it may not be feasible to train all nurses from a centre by offering only two training opportunities and perhaps additional training opportunities should be offered.

\subsection{Nurses' confidence to implement the $S N \subseteq P$}

Overall, nurses felt confident to apply the SN@P within their daily clinical routine. However, some nurses were not fully convinced they could accomplish this type of semi-structured consultation with high fidelity. It is plausible that educational preparation and oncology experience might have influenced perceived confidence for providing such a complex intervention involving relatively high level communication skills (EONS, 2018; Gaguski et al., 2017). Nursing leaders could play an important role in supporting nurses and facilitate behaviour change (i.e. delivering the intervention) (Bryant-Lukosius et al., 2016; Sharma et al., 2018).

Work-related factors associated with nurses' confidence in implementing the $S N @ P$

Mean Work-SoC scores in this study were similar to those observed in a study testing the instrument's validity (mean $\pm \mathrm{SD}=5.10 \pm 0.89$ vs. $5.30 \pm 0.93$ respectively) (Bauer et al., 2015). It seems that the work situation at participating centres might have influenced nurses' confidence to implement semi-structured SNCP consultations within clinical daily routines. Due to the limited number of nurses attending the followup training $(n=14)$, the significant correlation between overall WorkSoC score and nurses' perceived confidence to integrate educational consultations within daily clinical routines should be interpreted with caution. Nevertheless, this finding is consistent with the COM-B model that posits individual beside knowledge, motivation and work-related factors influence behaviour change (Michie et al., 2011). Given the initial findings, we plan to use focus groups in ongoing studies to further explore the role of work environment factors in implementing the $\mathrm{SN} \odot \mathrm{P}$ in ongoing work.

\section{Limitations}

Best practices call for evaluating novel complex interventions in pilot studies to examine feasibility of introducing a new intervention under real life conditions as well as for exploring effect sizes prior to conducting appropriately-powered clinical trials (Craig et al., 2008; Morris and Rosenbloom, 2017). Due to the limited sample of trained nurses $(n=21)$, the results should be considered preliminary and interpreted with caution. Results from the current study may guide refinement of training content to enhance acceptability and improve nurses' confidence to implement the SNCP within their daily clinical routine.

In summary, we successfully implemented the SNCP in three outpatient cancer centres randomised to intervention clusters. However, the implementation of the SNCP was driven by nurses who were motivated to enhance self-management support at their centres. Therefore, acceptability of the training at other, potentially less motivated, centres might be different. The three centres with successful implementation were in urban areas yet we were unable to successfully implement the $\mathrm{SN} @ \mathrm{P}$ at the lone rural centre due to a significant decrease in patients receiving anti-cancer treatments at that centre. Accordingly, feasibility of implementing the SNCP at rural centres merits further investigation.

Herein we described the training content and nurses' evaluation of the training. However, we did not specifically report how nurses applied the SNCP at their respective centres. Nurses' fidelity to training manual and their evaluation of the SNCP within their daily clinical practice will be crucial for long-term implementation and sustainability.

\section{Implications for clinical application}

The small number of nurses participating in both training courses may point to logistical barriers for planning/conducting training. Such logistical roadblocks could limit broad dissemination and implementation of the SN@P. One potential avenue for mitigating such challenges may involve using an e-learning tool to offer asynchronous training for nurses. However, such individual e-learning experiences may not be acceptable as nurses expressed significant value in discussions and peer-to-peer learning. An e-learning tool introducing the $\mathrm{SN} \odot \mathrm{P}$ combined with a face-to-face follow-up training could be a potential mixed approach that would accommodate group-learning. 


\section{Conclusion}

The SN@P is a nurse-led program to enhance symptom self-management in patients diagnosed with cancer. The training prepared nurses to provide symptom self-management support and is a first step in standardising nurse-led self-management education for patients diagnosed with cancer. Based on our development process and the promising initial results, we believe the SNCP could help drive change in oncology nursing practice. The SNCP may help shift perspectives on self-management support from simply providing generic information to a more tailored approach empowering patients to self-manage symptoms.

\section{Funding acknowledgement}

The Symptom Navi@ Pilot Study received funding from: University of Applied Sciences and Arts Western Switzerland, School of Health Sciences Fribourg, Switzerland; Institute of Higher Education and Research in Health Care, Faculty of Biology and Medicine, University of Lausanne and Lausanne University Hospital, Switzerland; Centre Hospitalier Universitaire Vaudois (CHUV), Department of Oncology, Lausanne, Switzerland; Hospital Group Lindenhof, Bern, Switzerland; Swiss Cancer League, Bern, Switzerland; Dr. Hans Altschüler Stiftung, St. Gallen, Switzerland.

\section{CRediT authorship contribution statement}

Marika Bana: Conceptualization, Methodology, Formal analysis, Investigation, Writing - original draft, Project administration. Karin Ribi: Conceptualization, Writing - review \& editing, Validation, Supervision, Project administration. Susanne Kropf-Staub: Conceptualization, Methodology, Investigation, Writing - review \& editing. Ernst Näf: Conceptualization, Methodology, Writing - review \& editing. Monique Sailer Schramm: Conceptualization, Methodology, Formal analysis, Investigation, Writing - review \& editing. Sabin Zürcher-Florin: Conceptualization, Writing - review \& editing. Solange Peters: Conceptualization, Methodology, Writing - review \& editing. Manuela Eicher: Conceptualization, Methodology, Investigation, Validation, Writing - review \& editing, Project administration, Funding acquisition.

\section{Declaration of competing interest}

Solange Peters has received education grants, provided consultation, attended advisory boards, and/or provided lectures for: Abbvie, Amgen, AstraZeneca, Bayer, Biocartis, Boehringer-Ingelheim, BristolMyers Squibb, Clovis, Daiichi Sankyo, Debiopharm, Eli Lilly, F. Hoffmann-La Roche, Foundation Medicine, Illumina, Janssen, Merck Sharp and Dohme, Merck Serono, Merrimack, Novartis, Pharma Mar, Pfizer, Regeneron, Sanofi, Seattle Genetics and Takeda, from whom she has received honoraria. Manuela Eicher received education grants, provided consultation, attended advisory boards, and/or provided lectures for: Vifor, Roche, and Bristol-Myers Squibb. All other authors have no competing interests to declare.

\section{Acknowledgments}

We acknowledge Dr. rer. medic. Patrick Jahn and Prof. Dr. sc. (ETH) Susanne Look for their advise and support regarding study design and the evaluation of nurses' training, and Prof. Andrew Dwyer for editing the final manuscript. Further, we acknowledge all participating outpatient centres with local investigators and nurses who support the Symptom Navi@ Pilot Study: Gynäkologisches Tumorzentrum, Universitätsspital Basel: Prof. Dr. med. Viola A. Heinzelmann, Veronica Fasanella, Verena Fluri, Fabienne Hess, Eveline Schönau, Jasmina Kljajic, Franziska Schmidle, Helena Strebel, Shqipc Bucaliu; Hôpital fribourgeois - Meyriez-Murten: Prof. Dr. med. D. Betticher, Dr. med. Vérène Dougoud-Chauvin, Priska Koch, Claudia Schmid,
Sophie Renevey; Kantonsspital Aarau: Dr. med. Nathan Cantoni, Thomas Seger, Sina Brugger, Fatima Dos Santos Oliveira, Thomas Widmer, Stefan Büschl, Therese Grädel, Ursula Neumann, Denise Gloor; Kantonsspital Graubünden: Dr. med. Michael Schwitter, Barbara Stoffel, Sabrina Zortea, Anja Cathomas, Gabriela Manetsch; Brustzentrum Bern, Engeried Spital: Prof. Dr. med. Markus Borner, Dr. med. Michele Ciriolo, Chantal Schneider, Isabelle Steiner, Anja Blunschi, Ditte Immoberdorf, Claudia Vögeli, Madeleine Dittens, Dr. med. Claudia Gübelin; Rundum Onkologie am Bahnhofpark Sargans: Dr.med. Stefan Greuter, Renata Marthy, Michela Winter, Diana Malin; Solothurner Spitäler AG - Kantonsspital Olten/ Bürgerspital Solothurn: Dr. med. Thomas Egger, Dr. med. Walter Mingrone, Dr. med. Andreas Barth, Dr. med. Simone Farese, Dr. med. Phillipe Von Burg, Dr. med. Grit Richartz, Sybille Wyss, Dr. med. Martin Kälin, Ernst Näf, Katrin Schnyder, Marlies Bogaert, Ruth Jordi, Anita Sidler, Marina Affolter; Spital STS AG - Thun: Dr. med. Jean-Marc Lüthi, Sandra Knettenmann, Nadja Rubin, Trudy Kuhn, Christine Kuhn, Francine Rieder Nicolet, Manuel Schnegg, Verena Flügel, Sadiku Fitore, Thorsten Dürmüller; Tumor-und Brustzentrum ZeTuP Rapperswil: Dr. med. Rudolf Morant, Dr. med. Iris Müller-Käser, Dr. med. Daniel Koychev, Lisa Haefliger, Isabel Carrard, Rebecca Biber, Susi BrunnerHeller.

\section{References}

Armes, J., Wagland, R., Finnegan-John, J., Richardson, A., Corner, J., Griffiths, P., 2014. Development and testing of the patient-reported chemotherapy indicators of symptoms and experience: patient-reported outcome and process indicators sensitive to the quality of nursing care in ambulatory chemotherapy settings. Cancer Nurs. 37, E52-E60.

Bana, M., Ribi, K., Kropf-Staub, S., Zurcher-Florin, S., Naf, E., Manser, T., Butikofer, L., Rintelen, F., Peters, S., Eicher, M., 2019. Implementation of the Symptom Navi (c) Programme for cancer patients in the Swiss outpatient setting: a study protocol for a cluster randomised pilot study (Symptom Navi(c) Pilot Study). BMJ Open 9, e027942.

Bauer, G.F., Vogt, K., Inauen, A., Jenny, G.J., 2015. Work-SoC-Development and validation of a scale measuring work-related sense of coherence. Z. für Gesundheitspsychol. 23, 20-30.

Bodenheimer, T., Lorig, K., Holman, H., Grumbach, K., 2002. Patient self-management of chronic disease in primary care. J. Am. Med. Assoc. 288, 2469-2475.

Braun, V., Clarke, V., 2006. Using thematic analysis in psychology. Qual. Res. Psychol. 3, 77-101.

Bryant-Lukosius, D., Spichiger, E., Martin, J., Stoll, H., Kellerhals, S.D., Fliedner, M., Grossmann, F., Henry, M., Herrmann, L., Koller, A., Schwendimann, R., Ulrich, A. Weibel, L., Callens, B., De Geest, S., 2016. Framework for evaluating the impact of advanced practice nursing roles. J. Nurs. Scholarsh. 48, 201-209.

Charalambous, A., Wells, M., Campbell, P., Torrens, C., Ostlund, U., Oldenmenger, W., Patiraki, E., Sharp, L., Nohavova, I., Domenech-Climent, N., Eicher, M., Farrell, C., Larsson, M., Olsson, C., Simpson, M., Wiseman, T., Kelly, D., 2018. A scoping review of trials of interventions led or delivered by cancer nurses. Int. J. Nurs. Stud. 86, $36-43$.

Cockle-Hearne, J., Faithfull, S., 2010. Self-management for men surviving prostate cancer: a review of behavioural and psychosocial interventions to understand what strategies can work, for whom and in what circumstances. Psycho Oncol. 19, 909-922.

Coolbrandt, A., Dierckx de Casterle, B., Wildiers, H., Aertgeerts, B., Van der Elst, E., van Achterberg, T., Milisen, K., 2016. Dealing with chemotherapy-related symptoms at home: a qualitative study in adult patients with cancer. Eur. J. Cancer Care 25, 79-92.

Coolbrandt, A., Steffens, E., Wildiers, H., Bruyninckx, E., Verslype, C., Milisen, K., 2017. Use of a symptom diary during chemotherapy: a mixed-methods evaluation of the patient perspective. Eur. J. Oncol. Nurs. 31, 37-45.

Coolbrandt, A., Wildiers, H., Laenen, A., Aertgeerts, B., Dierckx de Casterle, B., van Achterberg, T., Milisen, K., 2018. A nursing intervention for reducing symptom burden during chemotherapy. Oncol. Nurs. Forum 45, 115-128.

Craig, P., Dieppe, P., Macintyre, S., Michie, S., Nazareth, I., Petticrew, M., Medical Research Council, G., 2008. Developing and evaluating complex interventions: the new Medical Research Council guidance. BMJ 337, a1655.

de Silva, D., 2011. Evidence: Helping People Help Themselves. Health Foundation.

Dubey, C., De Maria, J., Hoeppli, C., Betticher, D.C., Eicher, M., 2015. Resilience and unmet supportive care needs in patients with cancer during early treatment: a descriptive study. Eur. J. Oncol. Nurs. 19, 582-588.

EONS, E.O.N.S., 2018. The EONS Cancer Nursing Education Framework. European Oncology Nursing Society (online). https://www.cancernurse.eu/documents/ EONSCancerNursingFramework2018.pdf.

Ferrell, B., McCabe, M.S., Levit, L., 2013. The Institute of Medicine report on high-quality cancer care: implications for oncology nursing. Oncol. Nurs. Forum 40, 603-609.

Fitch, M.I., 2008. Supportive care framework. Can. Oncol. Nurs. J. 18, 6-24. 
Gaguski, M.E., George, K., Bruce, S.D., Brucker, E., Leija, C., LeFebvre, K.B., Mackey, H., 2017. Oncology nurse generalist competencies: oncology nursing society's initiative to establish best practice. Clin. J. Oncol. Nurs. 21, 679-687.

Giesinger, J.M., Wintner, L.M., Zabernigg, A., Gamper, E.M., Oberguggenberger, A.S., Sztankay, M.J., Kemmler, G., Holzner, B., 2014. Assessing quality of life on the day of chemotherapy administration underestimates patients' true symptom burden. BMC Canc. 14, 758 .

Griffiths, P., Richardson, A., Blackwell, R., 2012. Outcomes sensitive to nursing service quality in ambulatory cancer chemotherapy: systematic scoping review. Eur. J. Oncol. Nurs. 16, 238-246.

Hammer, M.J., Ercolano, E.A., Wright, F., Dickson, V.V., Chyun, D., Melkus, G.D., 2015. Self-management for adult patients with cancer an integrative review: an integrative review. Cancer Nurs. 38, E10-E26.

Hild, P., 2013. Kooperatives Lernen im Hochschulbereich. In: Bachmann, H. (Ed.), Hochschullehre variantenreich gestalten, Kompetenzorientierte Hochschullehre Ansätze, Methoden und Beispiele. hep verlag ag, Bern.

Hoffman, A.J., 2013. Enhancing self-efficacy for optimized patient outcomes through the theory of symptom self-management. Cancer Nurs. 36, E16-E26.

Howell, D., Harth, T., Brown, J., Bennett, C., Boyko, S., 2017. Self-management education interventions for patients with cancer: a systematic review. Support. Care Cancer 25, 1323-1355.

Irwin, M., Johnson, L.A., 2014. Putting evidence into practice, A pocket guide to cancer symptom management. Oncol. Nurs. Soc ASIN: B00O18L286.

Kropf-Staub, S., Sailer Schramm, M., Preusse-Bleuler, B., Eicher, M., Zürcher, S., 2017a. Flyer Symptom Navi zur Unterstützung des Selbstmanagements von Symptomen bei Krebs: evaluation von Anwendbarkeit und Verständlichkeit. Pflege 30, 151-160.

Kropf-Staub, S., Sailer Schramm, M., Zürcher, S., Näf, E., Eicher, M., 2017b. Symptom Navi program - entwicklung 2011 - 2015. Onkologische Pflege 7, 21-27.

Lewis, L., Williams, A.M., Athifa, M., Brown, D., Budgeon, C.A., Bremner, A.P., 2015. Evidence-based self-care guidelines for people receiving chemotherapy: do they reduce symptom burden and psychological distress? Cancer Nurs. 38, E1-E8.

Lorig, K.R., Holman, H.R., 2003. Self-management education: history, definition, outcomes, and mechanisms. Ann. Behav. Med. 26, 1-7.

Luckett, T., Davidson, P.M., Green, A., Boyle, F., Stubbs, J., Lovell, M., 2013. Assessment and management of adult cancer pain: a systematic review and synthesis of recent qualitative studies aimed at developing insights for managing barriers and optimizing facilitators within a comprehensive framework of patient care. J. Pain Symptom Manag. 46, 229-253.

McCorkle, R., Ercolano, E., Lazenby, M., Schulman-Green, D., Schilling, L.S., Lorig, K., Wagner, E.H., 2011. Self-management: enabling and empowering patients living with cancer as a chronic illness. CA A Cancer J. Clin. 61, 50-62.
Michie, S., Atkins, L., West, R., 2014. The Behaviour Change Wheel, A Guide to Designing Interventions. Silverback Publishing, Great Britain.

Michie, S., Fixsen, D., Grimshaw, J.M., Eccles, M.P., 2009. Specifying and reporting complex behaviour change interventions: the need for a scientific method. Implement. Sci. 4, 40.

Michie, S., van Stralen, M.M., West, R., 2011. The behaviour change wheel: a new method for characterising and designing behaviour change interventions. Implement. Sci. 6,42 .

Morris, N.S., Rosenbloom, D.A., 2017. CE: defining and understanding pilot and other feasibility studies. Am. J. Nurs. 117, 38-45.

Polit, D.F., Beck, C.T., 2006. The content validity index: are you sure you know what's being reported? Critique and recommendations. Res. Nurs. Health 29, 489-497.

Reeve, B.B., Mitchell, S.A., Dueck, A.C., Basch, E., Cella, D., Reilly, C.M., Minasian, L.M., Denicoff, A.M., O'Mara, A.M., Fisch, M.J., Chauhan, C., Aaronson, N.K., Coens, C., Bruner, D.W., 2014. Recommended patient-reported core set of symptoms to measure in adult cancer treatment trials. J. Natl. Cancer Inst. 106.

Rollnick, S., Miller, W.R., Butler, C.C., 2008. Motivational Interviewing in Health Care, Helping Patients Change Behavior. The Guilford Press, New York.

Schofield, P., Chambers, S., 2015. Effective, clinically feasible and sustainable: key design features of psycho-educational and supportive care interventions to promote individualised self-management in cancer care. Acta Oncol. 805-812.

Serena, A., Griesser, A.-C., Débarge, P., Fucina, N., Peters, S., Eicher, M., 2012. Unmet supportive care needs of lung cancer patients during the chemotherapy phase: a descriptive study. Schweizer Krebsbulletin 118-122.

Sharma, N., Herrnschmidt, J., Claes, V., Bachnick, S., De Geest, S., Simon, M., Match, R.N.S.G., 2018. Organizational readiness for implementing change in acute care hospitals: an analysis of a cross-sectional, multicentre study. J. Adv. Nurs. 74, 2798-2808. https://doi.org/10.1111/jan.13801.

Vogt, K., Jenny, G.J., Bauer, G.F., 2013. Comprehensibility, Manageability and Meaningfulness at Work: Construct Validity of a Scale Measuring Work-Related Sense of Coherence.

Wagland, R., Richardson, A., Armes, J., Hankins, M., Lennan, E., Griffiths, P., 2015. Treatment-related problems experienced by cancer patients undergoing chemotherapy: a scoping review. Eur. J. Cancer Care 24, 605-617.

Watson, E.K., Shinkins, B., Matheson, L., Burns, R.M., Frith, E., Neal, D., Hamdy, F., Walter, F.M., Weller, D., Wilkinson, C., Faithfull, S., Sooriakumaran, P., Kastner, C. Campbell, C., Neal, R.D., Butcher, H., Matthews, M., Perera, R., Wolstenholme, J., Rose, P.W., 2018. Supporting prostate cancer survivors in primary care: findings from a pilot trial of a nurse-led psycho-educational intervention (PROSPECTIV). Eur. J. Oncol. Nurs. 32, 73-81. 